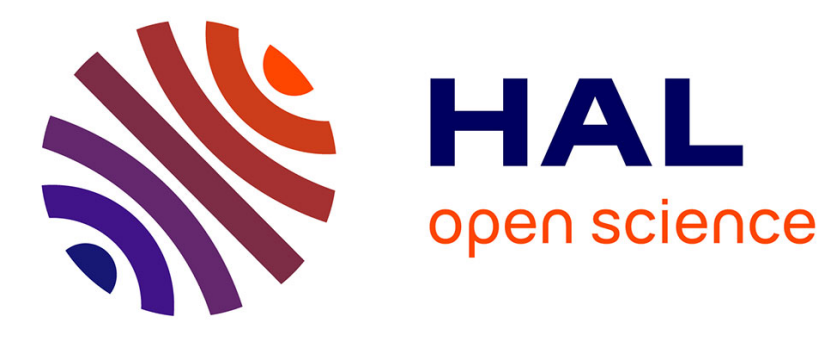

\title{
Post-stroke follow-up: Time to organize
}

Etienne Santos, S. Broussy, E. Lesaine, F. Saillour, F. Rouanet, Patrick

Dehail, Pierre-Alain Joseph, F. Aly, Igor Sibon, Bertrand Glize

\section{To cite this version:}

Etienne Santos, S. Broussy, E. Lesaine, F. Saillour, F. Rouanet, et al.. Post-stroke follow-up: Time to organize. Revue Neurologique, 2019, 175 (1-2), pp.59-64. 10.1016/j.neurol.2018.02.087 . hal03210835

\section{HAL Id: hal-03210835 \\ https://hal.science/hal-03210835}

Submitted on 22 Oct 2021

HAL is a multi-disciplinary open access archive for the deposit and dissemination of scientific research documents, whether they are published or not. The documents may come from teaching and research institutions in France or abroad, or from public or private research centers.
L'archive ouverte pluridisciplinaire HAL, est destinée au dépôt et à la diffusion de documents scientifiques de niveau recherche, publiés ou non, émanant des établissements d'enseignement et de recherche français ou étrangers, des laboratoires publics ou privés.

\section{다)(1) $(5$}

Distributed under a Creative Commons Attribution - NonCommerciall 4.0 International 


\title{
Post-stroke follow-up: time to organize
}

\author{
Etienne SANTOS MD ${ }^{1}$, Sophie BROUSSY MD ${ }^{3,4}$, Emilie LESAINE MD ${ }^{3,4}$, Florence \\ SAILLOUR MD ${ }^{3,4}$, François ROUANET MD ${ }^{4,5}$, Patrick DEHAIL MD PhD ${ }^{1,2}$, Pierre-Alain \\ JOSEPH MD ${ }^{1,2}$, Florence ALY MD 2 , Igor SIBON MD PhD ${ }^{5}$, Bertrand GLIZE MD ${ }^{1,2}$ \\ ${ }^{1}$ EA4136 Handicap Activity Cognition Health, University of Bordeaux, France \\ ${ }^{2}$ Department of Physical Medicine and Rehabilitation, Bordeaux University Hospital, Bordeaux, France \\ ${ }^{3}$ Pôle de sante publique, Bordeaux University Hospital, Bordeaux University, F-33000 Bordeaux, France \\ ${ }^{4}$ Observatoire Aquitain ObA2, CCECQA, Bordeaux University Hospital, Bordeaux, France \\ ${ }^{5}$ Neurology, Stroke Unit, INCIA CNRS UMR 5287, Bordeaux University Hospital, University of Bordeaux, \\ France
}

Running head: Post-stroke follow-up

\section{Corresponding author:}

Dr Bertrand GLIZE

Place Amélie Raba Léon, service MPR, 33076 Bordeaux, France

Phone: +33 5567955 46, Fax: +33 556796006

Email: bertrand.glize@chu-bordeaux.fr 


\section{ABSTRACT}

Background/objective: General practitioners (GPs) are pivotal in the organization of the entire post-stroke management system. This study aimed to examine the sequelae of chronic post-stroke patients and to assess whether the medical follow-up organized by GPs is truly in accordance with current recommendations and patients' clinical needs.

Methods: This was an observational study including chronic post-stroke patients after a first stroke. Their post-stroke follow-ups (visits to GPs and specialist doctors) were compared with guidelines and with clinical needs as evaluated through a number of questionnaires.

Results: Overall, 53.2\% of patients visited a neurologist as recommended and, although 49.4\% had neuropsychiatric consequences, only $6.3 \%$ visited a psychiatrist. Similarly, while $34.2 \%$ had significant post-stroke disability, only $6.3 \%$ saw a rehabilitation physician.

Conclusion: Taking into account not only cardiovascular prevention, but all post-stroke consequences, medical follow-ups as organized by GPs were not in accordance with recommendations and failed to take advantage of the currently available multidisciplinary resources required to improve patients' needs.

Key words: Stroke; General practice; Follow-up; Health resources; Neuropsychiatric impairment 


\section{INTRODUCTION}

Post-stroke patient follow-up is mandatory for optimizing secondary stroke prevention and identifying post-stroke physical, cognitive and neuropsychiatric complications, the major sources of disability and impaired quality of life in such patients [1]. International guidelines, including French ones, suggest standardized post-stroke management [2-5] to decrease the impact of post-stroke sequelae. In France as in many other countries, general practitioners (GPs) are the first point of contact with the healthcare system, and almost all patients follow a coordinated care pathway. Indeed, GPs provide primary care and have to organize referral to specialists when necessary [6] and, therefore, are supposed to gather together all patients' medical information.

While the role of GPs should be pivotal in post-stroke care [7], some differences may arise compared with stroke neurologists, and may provide a rationale for the assistance of networks involving multidisciplinary medical personnel. However, in several other countries, a few studies focusing only on secondary cardiovascular prevention have suggested that GP training and experience are less than optimal [8-13]. Post-stroke sequelae also extend to all other aspects of a patient's life, yet to our knowledge, only one previous study has focused on these other aspects, including disabilities and psychological impairment, and also explored GPs' perception of patients' disabilities in a small sample of patients with relatively mild complications. In fact, the authors suggested that this perception and patients' needs assessment by GPs are still lacking [14], making their prescribed management insufficient.

To optimize medical follow-up, French guidelines $[4,5,15]$ recommend a visit to a GP within the first month of discharge from the stroke unit, and then every 3 months. In addition, they also recommend that GPs refer patients to specialized doctors to further assess and manage their health needs. Since 2003 (but actualized in 2007 and 2015) [4, 5, 15], these guidelines 
have also recommended that patients systematically visit a neurologist within 6 months of having a stroke to optimize management of their post-stroke sequelae and treatment. Where necessary, they should also visit other specialists (such as cardiologists, rehabilitation specialists and/or psychiatrists) if specific cardiological, physical, cognitive and/or neuropsychiatric impairments are detected $[4,5,15]$.

However, one important question that remains to be investigated is whether this entire system of post-stroke management and medical follow-up, as organized by GPs, is truly in accordance with the guidelines and make proper use of the currently available multidisciplinary resources. Thus, the present study aimed to compare the medical follow-up and paramedical care organized by GPs against patients' needs and current guidelines during the first post-stroke year.

\section{METHODS}

This study enrolled patients 14 to 16 months after a first stroke between 1 October and 4 December 2013 in Southwest France as well as their GPs, and was part of a larger publichealth program investigating post-stroke sequelae, patients' needs and quality of life. The protocols of both studies were approved by the ethics committee of our university.

Patients' inclusion criteria were: first ischemic or hemorrhagic stroke confirmed by neuroimaging and managed at a stroke unit; return to their usual place of residence at the time of evaluation; valid phone number recorded during the initial hospitalization; age > 18 years; and a GP willing to participate in a specific interview. All patients either had a scheduled visit with a neurologist or a recommendation to organize such a visit included in their hospital records for GPs. All GPs who agreed to participate had no specific requirements for inclusion. 
Patients' exclusion criteria were: death before follow-up; and severe cognitive impairment or aphasia likely to impede their ability to answer questionnaires (by phone and posted mail).

To identify clinical needs, patients had to answer interviewer-administered questionnaires over the phone and to fill in self-administered questionnaires (in French, validated in a poststroke population and with assistance in cases of motor impairment) sent through the post (with prepaid return envelopes). Interviewer-administered questionnaires assessed handicaps and disabilities using a modified Rankin Scale (mRS) score $(0=$ no handicap, $6=$ dead) [16], and cognitive impairment using the French Modified Telephone Interview for Cognitive Status (TICS) with scores ranging from 0 to $43(<25=$ cognitive impairment $)$ [17]. Selfadministered questionnaires evaluated measures of: health status using the EQ-5D-3L instrument, with scores ranging from $5=$ no health problem to $15=$ major health problem $[18$, 19]; social integration using the Community Integration Questionnaire (CIQ), with scores ranging from $0=$ no integration to $29=$ maximum integration [20]; limitations on activities of daily living (ADLs) using the Barthel index, with scores ranging from 0 to $100(<80=$ limitations on ADLs) [21]; fatigue using the Fatigue Severity Scale (FSS), with scores ranging from 1 to 7 (> 5 = presence of fatigue) [22]; and anxiety and depression using the Hospital Anxiety and Depression Scale (HADS), with scores ranging from 0 to $42(>14=$ symptoms of anxiety and depression) [23]. Initial stroke severity, as assessed by the US National Institutes of Health Stroke Scale (NIHSS) [24], was also recorded.

Patients' medical follow-ups were assessed by telephone interviews with their GPs, which were scheduled ahead of time to ensure access to patients' medical information and collected the following data: number of GP visits; reason for each visit; evaluations (organized or not by GPs) by specialists, including neurologists, cardiologists, rehabilitation physicians, geriatricians and/or psychiatrists, at least once within the post-stroke year. In addition, any 
paramedical/rehabilitation care and follow-up involving a physiotherapist, nurse, occupational therapist, speech therapist and/or psychologist were also recorded.

In addition, specific characteristics of the participating GPs, such as age, number of years of medical practice, place of practice (rural, semirural, urban), and distance between the practice and the patient's home, were recorded.

The study first assessed the medical follow-up to determine whether it was in line with guidelines (for example, a GP visit during the first month after discharge from the stroke unit and then every 3 months, and a visit to a neurologist). Data from patients who had seen a neurologist were then compared with data from patients who had not, using Student's $t$ test for quantitative data, chi-squared tests for qualitative data and Fisher's exact test for binary data. The same analyses were performed for patients who visited a cardiologist $v$ s patients who did not. In addition, to determine whether healthcare resources were in line with patients' clinical needs, the same tests were used to compare physiotherapist and/or nurse follow-ups with patients' handicaps, limitations in ADLs and health status scores (mRS, Barthel index, EQ-5D-3L), and also speech therapist follow-ups and cognitive (TICS) scores. To compare the patients analyzed (whose GPs were willing to participate) with patients whose GPs were not, the same analyses were again performed to identify their clinical characteristics and needs. A $P$ value $<0.05$ was considered statistically significant.

\section{RESULTS}

Of the 250 patients identified according to our inclusion/exclusion criteria, 79 answered the required questionnaires and had a GP willing to participate who could be contacted, and were analyzed for our study (Figure 1). No significant clinical differences $(P>0.05)$ were observed between patients included in the analysis and those who returned questionnaires but whose 
GPs were unwilling to participate (Table S1; see supplementary materials related to this article). Twelve GPs refused to participate or declared having no time to do so, two others were retired and 56 could not be reached after at least three attempts. The main clinical characteristics of the study population are summarized in Table 1 . Overall, $22.7 \%$ of patients had limitations in ADLs (Barthel index scores < 80), 34.2\% had moderate or severe disability requiring help (mRS scores > 2), 20.3\% had cognitive impairment (TICS scores < 25), 45.6\% had post-stroke fatigue (FSS scores > 5) and 49.4\% had neuropsychiatric consequences with anxiety and/or depression (HADS scores > 14).

Regarding medical follow-ups, only one patient failed to visit a GP within the first month of discharge from the stroke unit and then every 3 months. The median number of visits with a GP was 10 [interquartile range (IQR): 7-16]. The main reason for these visits was related to stroke follow-up (96.2\%), including cardiovascular prevention. As for follow-ups by a specialist, only 42 patients (53.2\%) saw a neurologist, as recommended by guidelines. In addition, $66(83.6 \%)$ visited a cardiologist, 35 (44.3\%) saw both a neurologist and a cardiologist; five $(6.3 \%)$ visited a rehabilitation physician, four $(5.1 \%)$ visited a geriatrician and five $(6.3 \%)$ saw a psychiatrist.

Patients who saw a neurologist had significantly more disability, as assessed by their mRS scores $(P=0.019)$, and poorer health status, as assessed by the EQ-5D-3L $(P=0.049)$. No significant association was observed with any other variables (Table 2). In fact, the only variable significantly associated $(P=0.016)$ with visiting a cardiologist was gender, with men being more frequently evaluated than women (Table S2; see supplementary materials related to this article).

Regarding paramedical care, 35 patients $(44.3 \%)$ were followed-up by a physiotherapist, 21 $(26.6 \%)$ by a speech therapist, six $(7.6 \%)$ by a psychologist, three $(3.8 \%)$ by an occupational 
therapist and $23(29.1 \%)$ by a nurse. The main reasons for nursing care were assistance/initiation of treatment (80\%), and a need for nursing and hygiene care $(65.2 \%)$.

A total of 15 GPs reported difficulty organizing a visit with a specialist due to a poor medical network, and six reported limited access of their patients to physiotherapy and/or speech therapy at home. Of these GPs' patients, $12(80 \%)$ had a follow-up with a neurologist and 12 (80\%) saw a cardiologist; however, every patient with a Barthel index score $<80$ benefited from physiotherapy.

Patients receiving nursing care had significantly more disability, more limitations in ADLs and poorer health status as assessed by mRS $(P<0.001)$, Barthel index $(P<0.001)$ and EQ5D-3L $(P<0.001)$ scores, respectively, compared with patients followed by a physiotherapist. Finally, speech therapist interventions were not significantly associated with cognitive impairment, as assessed by TICS scores $(P=0.893)$. These results are presented in Table 3.

\section{DISCUSSION}

This 1-year study of medical post-stroke management identified three main results: $(i)$ the frequency of GP evaluations was in accordance with current recommendations; (ii) neurologists are still insufficiently involved in stroke follow-up despite recommendations; and (iii) there is still a gap between patients' needs and currently available multidisciplinary resources, such as specialists like rehabilitation physicians, psychiatrists and speech therapists.

In addition, our present study has indicated that only half of these stroke patients were evaluated by a neurologist as recommended for post-stroke management. This lack of adherence to guidelines is evidently not influenced by limited access to specialists, given the 
higher rate of recommended follow-ups for these patients in their GP reports, nor by any bias of our GP sample, whose characteristics were similar to those of other GPs in the area [25]. Post-stroke evaluation by a neurologist has several objectives, including optimizing pharmacological and non-pharmacological secondary prevention, evaluating stroke mechanisms, and detecting the presence of physical complications, cognitive impairment and neuropsychiatric complaints. However, it is also of particular importance because GPs' perceptions of their patients' disabilities are still inadequate [14].

Indeed, the present findings demonstrate that patients followed by neurologists have higher levels of residual physical handicap, whereas no differences in cognitive and neuropsychiatric complications were observed. This suggests that physical disability is still given more consideration than 'invisible' psychoemotional handicaps. Moreover, these patients were only marginally followed by rehabilitation physicians even though more than one in five had significant residual physical disability. Likewise, despite almost half the patients having significant anxiety or depressive post-stroke complications, referral to a psychiatrist was only marginal, again suggesting the insufficient medical follow-up of these patients.

These findings highlight how underestimated neuropsychiatric post-stroke complications are, even though they are well known to impair post-stroke rehabilitation and quality of life [26]. Moreover, it is surprising to see that patients with cognitive impairment are not significantly more often followed-up by a speech therapist, despite speech therapy being a first-line treatment for post-stroke cognitive/language disorders in ambulatory care.

Regarding secondary cardiovascular prevention, even though this was not explored directly, our results suggest that this is the focus of most GPs, given the high rate of scheduled followups with a cardiologist (> 80\%). Secondary cardiovascular prevention is an important part of the national guidelines; as GPs are aware of this, they optimize medical treatments according 
to the rules of cardiovascular risk management, and some studies currently underway are exploring the efficiency of such management by GPs [27]. However, there are data to suggest suboptimal secondary prevention of high blood pressure and cholesterol, and less use of oral anticoagulation when follow-up is by GPs alone [8-13]. Thus, it is likely that collaborations between GPs and specialized resources (such as stroke neurologists and cardiologists) for more complex cases and the provision of clear individualized guidelines could ensure improvement of long-term follow-ups.

Nevertheless, the results of our present study need to be interpreted cautiously due to the small sample size and the inclusion of patients who returned to their places of living after their stroke. Moreover, visits scheduled by the GP but not carried through by the patient were not taken into account. While the consequences would remain the same-the provision of less-than-optimal post-stroke management - the causes would be different. Thus, the attitude and involvement of post-stroke patients also need to be improved through therapeutic education programs to further prevent inefficient post-stroke management.

\section{CONCLUSION}

Our present study findings suggest that GPs are mostly focused on dependence/motor impairment and cardiovascular secondary prevention while apparently underestimating cognitive/emotional impairments, as also noted for patients with transient ischemic attacks [28]. GPs will continue to play an important role in the proximity care of post-stroke followup and cardiovascular prevention; however, they should also receive regular training in the detection of 'invisible' post-stroke complications. This points to the importance of strengthening the entire healthcare network and creating multidisciplinary teams involving different contributors to post-stroke management. Although the conclusions of the present 
study are in line with the latest recommendations of the French Healthcare System to create such multidisciplinary teams and to schedule each patient for a multidisciplinary consultation [29], in the face of the low rate of patients who actually visited a neurologist, applying these recommendations still requires hard work to optimize their intended results.

\section{Declaration of conflicts of interest}

The authors declare no conflicts of interest 


\section{REFERENCES}

[1]. Murray CJ, Vos T, Lozano R, et al. Disability-adjusted life years (DALYs) for 291 diseases and injuries in 21 regions, 1990-2010: a systematic analysis for the Global Burden of Disease Study 2010. Lancet. 2012 380: 2197-2223.

[2]. Steiner T, Al-Shahi Salman R, Ntaios G. The European Stroke Organisation (ESO) guidelines. Int J Stroke. 2014 9: 838-839.

[3]. Kernan WN, Ovbiagele B, Black HR, et al. Guidelines for the prevention of stroke in patients with stroke and transient ischemic attack: a guideline for healthcare professionals from the American Heart Association/American Stroke Association. Stroke. 2014 45: 2160-2236.

[4]. HAS Cdl. Prévention vasculaire après un infarctus cérébral ou un accident ischémique transitoire. Recommandations de bonnes pratiques Saint-Denis La plaine: HAS. 2015.

[5]. HAS Cdl. Accident vasculaire cérébral - Guide - Affection de longue durée. Recommandations de bonnes pratiques Saint-Denis La plaine: HAS. 2007 ALD-AVC-GM.

[6]. Com-Ruelle L, Dourgnon P, Paris V. Can physician gate-keeping and patient choice be reconciled in France? Analysis of recent reform. EUROHEALTH-LONDON-. 2006 12: 17.

[7]. $\quad$ Best C, Mead G. GPs have pivotal role in care of stroke patients. The Practitioner. 2010 254: 31-35.

[8]. Heeley EL, Peiris DP, Patel AA, et al. Cardiovascular risk perception and evidence--practice gaps in Australian general practice (the AusHEART study). Med J Aust. 2010 192: 254-259.

[9]. de Weerd L, Rutgers AW, Groenier KH, van der Meer K. Health care in patients 1 year poststroke in general practice: research on the utilisation of the Dutch Transmural Protocol transient ischaemic attack/cerebrovascular accident. Aust J Prim Health. 2012 18: 42-49.

[10]. Dregan A, Toschke MA, Wolfe CD, Rudd A, Ashworth M, Gulliford MC. Utility of electronic patient records in primary care for stroke secondary prevention trials. BMC Public Health. 2011 11: 86.

[11]. Filippi A, Bignamini AA, Sessa E, Samani F, Mazzaglia G. Secondary prevention of stroke in Italy. Stroke. 2003 34: 1010-1014.

[12]. Jessie Harrold BSc M, Allen M. Secondary stroke prevention best practice recommendations: exploring barriers for rural family physicians. Canadian journal of rural medicine. 2010 15: 143.

[13]. Bajorek BV, Magin PJ, Hilmer SN, Krass I. Optimizing Stroke Prevention in Patients With Atrial Fibrillation: A Cluster-Randomized Controlled Trial of a Computerized Antithrombotic Risk

Assessment Tool in Australian General Practice, 2012-2013. Prev Chronic Dis. 2016 13: E90.

[14]. Babin N, Theux G, Sibon I, et al. Patient and general practitioner perceptions of post-stroke difficulties may not always agree. Ann Phys Rehabil Med. 2017.

[15]. Anaes. Retour au domicile des patients adultes atteints d'accident vasculaire cérébral. Service des recommandations professionnelles et service évaluation économique. 2003.

[16]. Rankin J. Cerebral vascular accidents in patients over the age of 60. II. Prognosis. Scott Med J. 1957 2: 200-215.

[17]. Barber M, Stott DJ. Validity of the Telephone Interview for Cognitive Status (TICS) in poststroke subjects. Int J Geriatr Psychiatry. 2004 19: 75-79.

[18]. Robinson K, McEwan P, Currie C. PSR3 THE EVALUATION OF HEALTH RELATED UTILITY (EQ5D INDEX) AND RESOURCE USE IN PATIENTS WITH STROKE COMPLICATED BY UPPER AND LOWER LIMB SPASTICITY. Value in Health. 2005 8: 334-335.

[19]. Chevalier J, de Pouvourville G. Valuing EQ-5D using time trade-off in France. The European Journal of Health Economics. 2013 14: 57-66.

[20]. Ritchie L, Wright-St Clair VA, Keogh J, Gray M. Community Integration After Traumatic Brain Injury: A Systematic Review of the Clinical Implications of Measurement and Service Provision for Older Adults. Archives of Physical Medicine and Rehabilitation. 2014 95: 163-174.

[21]. Sinoff G, Ore L. The Barthel activities of daily living index: self-reporting versus actual performance in the old-old (> or = 75 years). J Am Geriatr Soc. 1997 45: 832-836. 
[22]. Kuppuswamy A, Clark EV, Turner IF, Rothwell JC, Ward NS. Post-stroke fatigue: a deficit in corticomotor excitability? Brain. 2015 138: 136-148.

[23]. Turner A, Hambridge J, White J, et al. Depression screening in stroke: a comparison of alternative measures with the structured diagnostic interview for the diagnostic and statistical manual of mental disorders, fourth edition (major depressive episode) as criterion standard. Stroke. 2012 43: 1000-1005.

[24]. Brott T, Adams HP, Olinger CP, et al. Measurements of acute cerebral infarction: a clinical examination scale. Stroke. 1989 20: 864-870.

[25]. CNOM. La démographie médicale en Région Aquitaine: Situation en 2015 Paris: Conseil national de l'Ordre des médecins (CNOM), 2015.

[26]. Robinson RG. The clinical neuropsychiatry of stroke: Cognitive, behavioral and emotional disorders following vascular brain injury: Cambridge University Press, 2006.

[27]. Dregan A, van Staa T, Mcdermott L, et al. Cluster randomized trial in the general practice research database: 2 . Secondary prevention after first stroke (eCRT study): study protocol for a randomized controlled trial. Trials. 2012 13: 181.

[28]. Turner G, Calvert M, Feltham M, Ryan R, Marshall T. Ongoing impairments following transient ischaemic attack: retrospective cohort study. European Journal of Neurology. 2016 23:

1642-1650.

[29]. DGOS. Instruction $n^{\circ}$ DGOS/R4/2015/262 du 3 août 2015 relative à l'organisation régionale des consultations d'évaluation pluri professionnelle post Accident Vasculaire Cérébral (AVC) et du suivi des AVC. Direction générale de l'organisation des soins (DGOS), 2015. 
Table 1 - Characteristics of the analyzed patients and their general practitioners.

\begin{tabular}{lc} 
Patients $(\mathbf{n}=\mathbf{7 9})$ & Clinical measures \\
\hline Age, mean (SD) & $71(11.4)$ \\
Women & $28(35.4 \%)$ \\
Ischemic stroke & $68(86.1 \%)$ \\
Initial stroke severity score (NIHSS) & $3(2-8.25)$ \\
Barthel index & $100(80-100)$ \\
Modified Rankin Scale score & $2(1-5)$ \\
Fatigue Severity Scale score & $4.8(3.4-5.9)$ \\
Hospital Anxiety and Depression Scale score & $16(11-19)$ \\
Community Integration Questionnaire score & $13(5-27)$ \\
EQ-5D-3L score* & $6.9(5.8-10.5)$ \\
Modified Telephone Interview for Cognitive Status score & $31(26-43)$ \\
\hline General practitioners (GPs) & \\
\hline Age, mean (SD) & $54.7(10.5)$ \\
Women & $17(21.5 \%)$ \\
Place of practice (urban/semirural/rural) & $33 / 25 / 21$ \\
Distance in km between GP office and patient's home & $2(1-4)$ \\
Number of years in medical practice & $27(18-34)$ \\
\hline Data are medians (interquartile range) or n (\%) unless otherwise specified; & \\
$*$ measure of health status; & \\
SD: standard deviation; NIHSS: National Institutes of Health Stroke Scale.
\end{tabular}


Table 2 - Association between patients' clinical measures and follow-up with a neurologist or not.

\begin{tabular}{|c|c|c|c|}
\hline & Neurologist visit $(n=42)$ & No neurologist visit $(n=37)$ & $P^{*}$ \\
\hline Age, mean (SD) & $72(11.6)$ & $70.1(11.3)$ & 0.477 \\
\hline Women & $15(35.7 \%)$ & $13(35.1 \%)$ & 0.538 \\
\hline Ischemic stroke & $33(78.6 \%)$ & $35(94.6 \%)$ & 0.082 \\
\hline Initial stroke severity score (NIHSS) & $3(1.5-9)$ & $3(2-6)$ & 0.673 \\
\hline Barthel index & $100(75-100)$ & $100(85-100)$ & 0.277 \\
\hline Modified Rankin Scale score & $2(1-3)$ & $1(1-2)$ & 0.019 \\
\hline Fatigue Severity Scale score & $4.6(3.4-6.3)$ & $4.9(3.5-5.8)$ & 0.768 \\
\hline Hospital Anxiety and Depression Scale score & $16(12-18)$ & $16(8-20)$ & 0.531 \\
\hline Community Integration Questionnaire score & $11(4-17)$ & $14.5(9.25-18)$ & 0.176 \\
\hline EQ-5D-3L score** & $9(6-10)$ & $7(6-9)$ & 0.049 \\
\hline Modified Telephone Interview for Cognitive Status score & $31(26.5-34.5)$ & $30.5(24.75-35.25)$ & 0.841 \\
\hline
\end{tabular}

Data are medians (interquartile range) or n (\%) unless otherwise stated; * by Student's $t$ test for quantitative data, Fisher's exact test for binary data; ** measure of health status;

SD: standard deviation; NIHSS: National Institutes of Health Stroke Scale. 
Table 3 - Association between paramedical care (follow-up by physiotherapist, nurse, speech therapist) and patients' clinical measures.

\begin{tabular}{|c|c|c|c|c|c|c|c|c|c|}
\hline & \multicolumn{2}{|c|}{ Physiotherapist } & \multirow[b]{2}{*}{$P^{*}$} & \multicolumn{2}{|c|}{ Nurse } & \multicolumn{4}{|c|}{ Speech therapist } \\
\hline & Yes $(n=35)$ & No $(n=44)$ & & Yes $(n=23)$ & No $(n=56)$ & $P^{*}$ & Yes $(n=21)$ & No $(n=58)$ & $P^{*}$ \\
\hline Age, mean (SD) & $73.7(11.3)$ & $68.8(11.3)$ & 0.062 & $75.3(10.6)$ & $69.2(11.5)$ & 0.033 & $69.5(12.0)$ & $71.5(11.4)$ & 0.499 \\
\hline Barthel index & $80(55-100)$ & $100(95-100)$ & $<0.001$ & $75(50-88.75)$ & $100(95-100)$ & $<0.001$ & $97.5(70-100)$ & $100(82.5-100)$ & 0.009 \\
\hline mRS score & $3(2-4)$ & $1(0-1.75)$ & $<0.001$ & $3(2-4)$ & $1(0-2)$ & $<0.001$ & $2(1-3.25)$ & $1(0-2.5)$ & 0.005 \\
\hline FSS score & $51(33-57)$ & $41(27.5-51.75)$ & 0.107 & $52.5(34.5-57.75)$ & $41(27-52)$ & 0.081 & $42.5(26.5-51.75)$ & $43(32.5-56)$ & 0.748 \\
\hline HADS score & $2(1-2)$ & $1.5(1-5)$ & 0.154 & $1(1-2)$ & $2(1-5)$ & 0.01 & $1(1-2)$ & $2(1-4.5)$ & 0.141 \\
\hline CIQ score & $6(4-13)$ & $16.5(12.25-19.75)$ & $<0.001$ & $4.5(3.25-11)$ & $16(11-19)$ & $<0.001$ & $13.5(7.5-18)$ & $14(6-18.5)$ & 0.201 \\
\hline EQ-5D-3L** score & $9(7-11)$ & $6(5.25-9)$ & $<0.001$ & $10(9-12)$ & $7(6-9)$ & $<0.001$ & $8(6-10.5)$ & $7(6-9)$ & 0.011 \\
\hline Modified TICS score & $29(22-32)$ & $34(30-36.75)$ & 0.002 & $25(19-29.75)$ & $33(29-36)$ & $<0.001$ & $29.5(22-34.25)$ & $31(27-36)$ & 0.893 \\
\hline
\end{tabular}

Data are medians (interquartile range) or $\mathrm{n}(\%)$ unless otherwise specified; * by Student's $t$ test; ** measure of health status;

SD: standard deviation; mRS: modified Rankin Scale; FSS: Fatigue Severity Scale; HADS: Hospital Anxiety and Depression Scale; CIQ: Community Integration Questionnaire; TICS: Telephone Interview for Cognitive Status. 


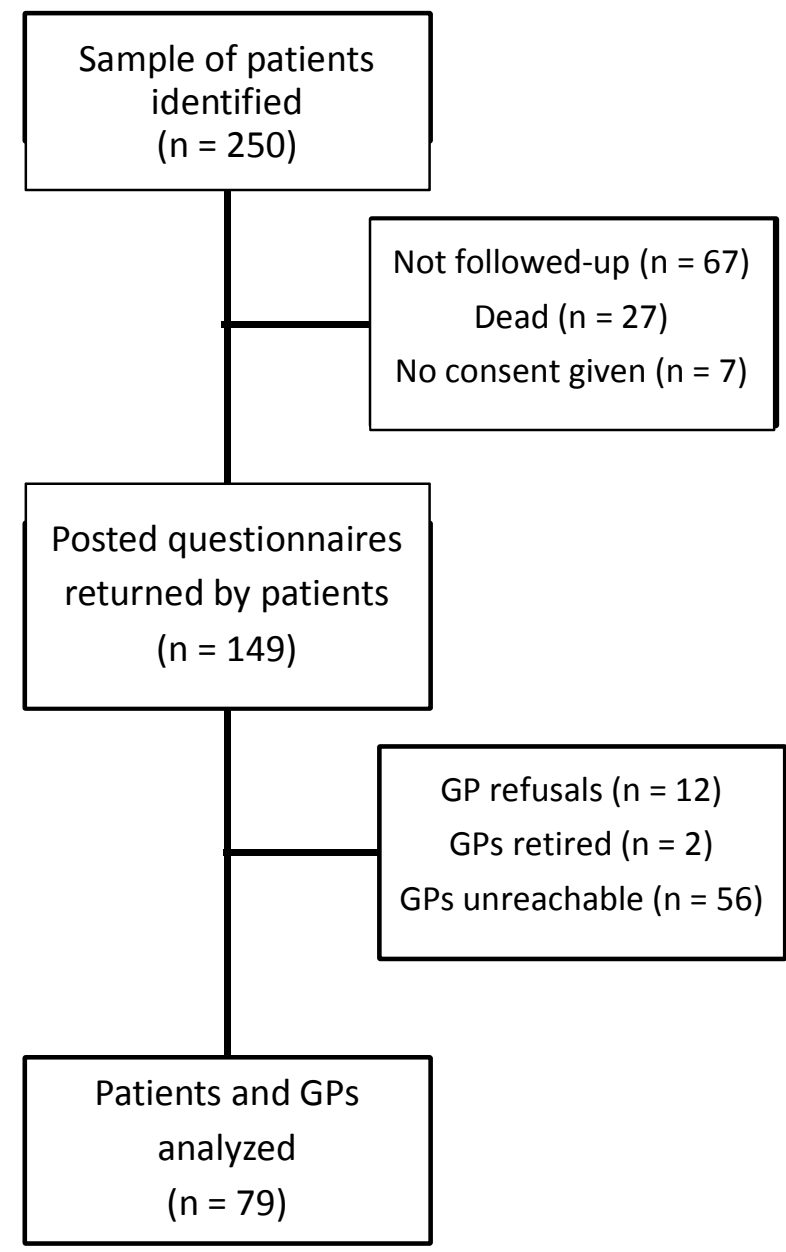

Fig. S1 - Flow chart of patient and general practitioner (GP) recruitment into the study. 